\title{
Fusarium infection of the maxillary sinus as a complication of overfilling of endodontic treatment: a case report
}

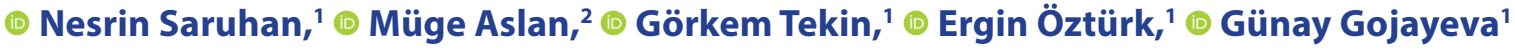 \\ 'Department of Oral and Maxillofacial Surgery, Eskişehir Osmangazi University Faculty of Dentistry, Eskişehir, Turkey \\ ${ }^{2}$ Department of Medical Microbiology, Health Sciences University, Haydarpaşa Numune Training and Research Hospital, istanbul, Turkey
}

Fusarium infections are rarely seen in maxillary sinus. When fusarium infections are seen; often is associated with lengthy antibiotic treatments, facial traumatic, nasal obstruction causing hypoxia and anaerobic conditions, and endosinal penetration with endodontic material after root canal treatment. The purpose of this case report is to present the treatment of foreign substances due to fusarium infections of the maxillary sinus with Caldwell-Luc procedure. 32-year-old female patient was admitted to our clinic with severe pain after endodontic treatment. At the result of the clinical and radiological findings, radiopaque material was found in left maxillary sinus. Fusarium-associated radiopaque material was removed by Caldwell-Luc surgery. Postoperative complications were not observed during radiological and clinical follow-up. Caldwell-Luc surgery, which is used for the removal of foreign substances related to fusarium infections in the maxillary sinus, is safe, less complicated, simple, rapid and successful method.

Keywords: Caldwell-Luc; endodontic treatment; fusarium infection; maxillary sinus; molar tooth.

$\mathrm{I}_{\mathrm{t}}^{\mathrm{t}}$ is generally accepted that the successful root canal treatment mainly depends on the suitable cleaning, canal shaping and proper obstruction of root canals. Various complications can be encountered during and after root canal treatment depending on the causes of over instrumentation and then extrusion of gutta-percha through the apical foramina. ${ }^{[1]}$

The fungus in root canals was first discovered by Grossman. He found fungus in $17 \%$ of the samples. ${ }^{[2]}$ The main etiological agents of the fungus were found as Candida, Penicillium, Aspergillus and Fusarium..$^{[3,4]}$ When it is accepted that root canal isolates are positive, Fusarium is a very rare opportunistic fungal infection. Fusarium infections have been occasionally reported in immunocom- promised hosts. ${ }^{[5]}$ The purpose of this case is to report whether the endodontic treatment of the molar tooth is a risk factor for Fusarium development and foreign materials in the maxillary sinus is removed by the Caldwell-Luc procedure.

\section{Case report}

A 32-year-old female patient referred to clinic with severe pain at the posterior maxillary region. The extraoral clinical examination revealed intense pain, mass swelling in the zygoma area, and sensivity in palpation. In the intraoral examination, it was seen that root canal retreatment had been done for the left maxillary first molar 2 weeks ago. In the radiographic examination, a radiopaque material was

Correspondence: Dr. Görkem Tekin. Eskişehir Osmangazi Üniversitesi Diş Hekimliği Fakültesi,

Meşelik Kampüsü, 26140 Eskişehir, Turkey.

Tel: +90 222 - 2393750 e-mail: dt.gorkemtekin@gmail.com

Submitted: June 10, 2018 Accepted: November 23, 2018

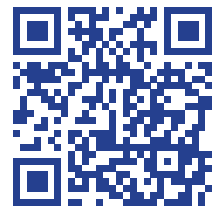


detected in the left maxillary sinus. It was thought to be root filling material (Fig. la).

After obtaining the patient's informed consent form, local anesthesia was applied maxillary posterior region and the affected tooth was removed. A vestibular incision was made from the canine to the first molar region and the full thickness mucoperiosteal flap was removed to reveal the fossa canine. A bone window was opened $4-5 \mathrm{~mm}$ in diameter distal to the apex of the canine and $5 \mathrm{~mm}$ above the apical of the premolars. The radiopaque material associated with fusarium was removed from maxillary sinus (Fig. lb). Maxillary sinus was irrigated and oroantral communication was closed successfully. The preliminary diagnosis of specimen was suspected to be fungal infections in which the appearance and character of the material in the sinus and was sent to the microbiology department. In associated with the Department of Microbiology at the University of Eskisehir Osmangazi, a sequence of laboratory assay was carried out on biopsy material and endodontic sealars.

\section{Results}

In laboratory, direct microscopic examination showed no cellular and microbiological factors. Fungal hyphae were seen in gram-stained preparations (Fig. lc). In addition, specimen Sabouraud dextrose agar (SDA) plaques were sown and incubated at $35^{\circ} \mathrm{C}$ for 7 days. In SDA, fastbreeding, cotton-colored, cream-colored and cream-colored pigmented colon colonies were identified. Fusarium spp. was identified as a possible agent because of the appearance of these colonies in the lactophenol-stained microscopic examination in the form of spindle-shaped, septal, thick-walled macroconidials located on short fyalids (Fig. ld). Antifungal susceptibility test was performed by microdilution method according to "Clinical and Laboratory Standards Institute (CLSI)" M38-A2 standard. MIC values were found to be amphotericin B $4 \mu \mathrm{g} / \mathrm{mL}$, fluconazole $0.5 \mu \mathrm{g} / \mathrm{mL}$, voriconazole $1 \mu \mathrm{g} / \mathrm{mL}$, posaconazole 4 $\mu \mathrm{g} / \mathrm{mL}$, caspofungin $4 \mu \mathrm{g} / \mathrm{mL}$ and anidulafungin $8 \mu \mathrm{g} /$ $\mathrm{mL}$. According to the CLSI M38-A2 standard, the resistance limit values for Fusarium species are not defined.

The intraoral evaluation of postoperative 1 week, oroantral communication wasn't seen and sutures were removed. It was seen that the complaints of the elderly patient did not have any pain and the patient was followed up.

\section{Discussion}

Maxillary fungal infections are the most common fungal disease developed without bone invasion in the unilateral maxillary sinus. It is usually seen in elderly individuals, especially in sixty-year-old patients, and has a female prepon-
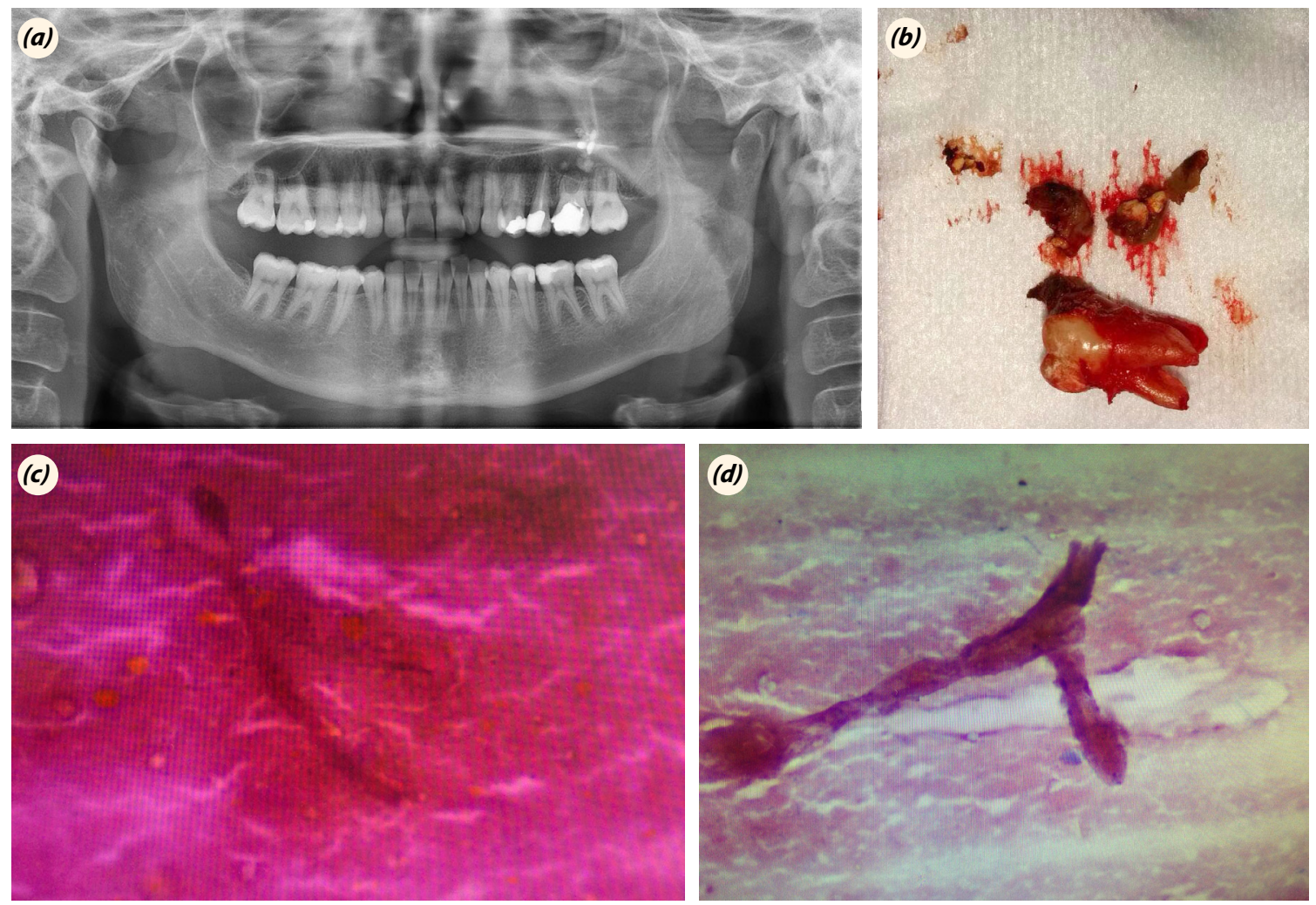

Fig. 1. (a) Preoperative radiographic image. (b) Tooth was extracted and sealer debris were carefully removed. (c, d) Microbiology section of Fusarium. 
derance ${ }^{[6]}$ Invasive fungal sinusitis is common in immunocompromised patients and the noninvasive fungal ball FB of the maxillary sinus is common in healthy individuals without fungal infection risk factors. The pathogenesis of the maxillary sinus FB is not known at large. However, it is generally thought that the maxillary is due to the inflammatory process associated with the dental procedures on the teeth. ${ }^{[7]}$ This case was reported after dental procedure on the left first maxillary tooth.

On clinical examination, usually, fusarium species can be cause of fungal sinusitis forms. These are allergic, chronic non-invasive $(\mathrm{FB})$ and invasive sinusitis. In the literature review showed that FB are usually cause of Aspergillus species but on the other hand particularly Fusarium species are so rare in the sinus. ${ }^{[8]}$ In our case report, symptoms like swelling, pain, sensitivity on palpation which causes from endodontic treatment in association with important surrounding structures tissues was seen. Relevantly, we saw a foreign body in the radiological examination, which we suspected was related to the symptoms of the left maxillary sinus.

The proximity of the maxillary teeth to the maxillary sinuses may cause the endodontic materials to accidentally overflow the maxillary sinuses. ${ }^{[9]}$ Literature results have shown that dental fillings with maxillary sinus can develop inflammation necrosis and FB in the maxillary sinus. Recent studies have shown that the risk of FB 14 times more than the patients without endodontic treatment in patients treated endodontically in the upper molar, premolars and canine teeth. Mensi et al. ${ }^{[7]}$ found that $89.2 \%$ of maxillary FB patients had endodontic treatment in maxillary teeth. Similarly Beck-Mannagetta et al. ${ }^{[10]}$ found that 33 (97\%) of 34 patients with maxillary sinus $\mathrm{FB}$ had undergone endodontic treatment in their teeth. There have been few studies in the literature of invasive Fusarium infection in previously healthy adults. ${ }^{[4,5]}$ Only two of them was a $F u$ sarium infection in maxillary sinus. ${ }^{[4,8]}$ The other studies in the literature were about open or penetrating injuries. All of which were secondary to open or penetrating injuries. In this case report, we thought that the Fusarium development due to the accumulation of seconder foreign body after the endodontic treatment. Furthermore, Fusarium infection is rare from other fungal infections because there are few published in the literature. It was seen in the left upper first molar root endodontic treatment.

Fusarium associated foreign material are easily removed in the maxillary sinus by Caldwell-Luc procedure. Conditions used by the Caldwell-Luc procedure include sinus densities and tumors, foreign bodies, oroantral fistula, maxillary osteonecrosis, epistaxis control, sinusitis with irreversible mucosal changes, mycotic fungal deposits and facial trauma. ${ }^{[11]}$ In our case, Fusarium infection was successfully removed by Caldwell-Luc procedure.

\section{Conclusion}

As a result; endodontic treatment of maxillary teeth may be an important risk factor for the development of maxillary $\mathrm{FB}$, not related with of previous tooth extraction. Clinicians should be careful not to insert endodontic seal plugs into the maxillary sinus during endodontic treatment. Caldwell-Luc surgery is still one of the most widely used methods today, with effective, safe and successful operation for removing Fusarium associated with foreign bodies.

\section{Acknowledgments}

The authors deny any conflicts of interest related to this study.

Conflict of interest: None declared.

\section{References}

1. Evren O, Adanır N. Kök kanal tedavisinde maksiller sinüse güta-perka taşirilmasi (Bir olgu sunumu). Süleyman Demirel Üniv Diş Hek Fak Derg 2009;1:44-8.

2. Grossman LI. Root Canal Therapy. 3rd ed. London: Henry Kimpton; 1952.

3. Bosi GR, de Braga GL, de Almeida TS, de Carli A. Fungus ball of the paranasal sinuses: Report of two cases and literature review. Int Arch Otorhinolaryngol 2012;16:286-90.

4. Gomes C, Fidel S, Fidel R, de Moura Sarquis MI. Isolation and taxonomy of filamentous fungi in endodontic infections. J Endod 2010;36:626-9.

5. Nuovo MA, Simmonds JE, Chacho MS, McKitrick JC. Fusarium solani osteomyelitis with probable nosocomial spread. Am J Clin Pathol 1988;90:738-41.

6. Park GY, Kim HY, Min JY, Dhong HJ, Chung SK. Endodontic treatment: a significant risk factor for the development of maxillary fungal ball. Clin Exp Otorhinolaryngol 2010;3:136-40.

7. Mensi M, Piccioni M, Marsili F, Nicolai P, Sapelli PL, Latronico N. Risk of maxillary fungus ball in patients with endodontic treatment on maxillary teeth: a case-control study. Oral Surg Oral Med Oral Pathol Oral Radiol Endod 2007;103:433-6.

8. Kurien M, Anandi V, Raman R, Brahmadathan KN. Maxillary sinus fusariosis in immunocompetent hosts. J Laryngol Otol 1992;106:733-6.

9. Saruhan N, Kılınç A, Tepecik T, Ertaş Ü. Foreign material in a maxillary sinus as a complication of root canal treatment: a case report. Turk Endod J 2016;1:96-8.

10. Beck-Mannagetta J, Necek D. Radiologic findings in aspergillosis of the maxillary sinus. Oral Surg Oral Med Oral Pathol 1986;62:345-9.

11. Tange RA. Some historical aspects of the surgical treatment of the infected maxillary sinus. Rhinology 1991;29:155-62. 